\title{
Oxytocin and Self-Consciousness
}

\author{
Valentina Colonnello ${ }^{1 *}$ and Markus Heinrichs ${ }^{1,2 *}$ \\ ${ }^{1}$ Laboratory for Biological and Personality Psychology, Department of Psychology, University of Freiburg, Freiburg, Germany, \\ ${ }^{2}$ Freiburg Brain Imaging Center, University Medical Center, University of Freiburg, Freiburg, Germany
}

Keywords: oxytocin, neuropeptide, consciousness, self, self-other perception

In recent years, the study of self-consciousness from neuroscience and psychobiological perspectives has flourished rapidly. The understanding of the brain areas involved in self-consciousness and the complex intertwining of self-consciousness levels has expanded greatly, and the awareness of neurotransmitter influence on self-consciousness has begun to emerge. Despite this, the neuropeptidergic influences on self-consciousness have been largely ignored However, recent studies of the neuropeptide oxytocin have yielded promising results that further our understanding of the psychobiological foundations of self-consciousness. Here, we argue that the oxytocinergic system plays a role in modulating several levels of self-consciousness, a conclusion that is usually underscored in interpretations of previous studies.

Several studies indicate, that the neuropeptide oxytocin plays a central role in social cognition (Heinrichs and Domes, 2008; Heinrichs et al., 2009). For example, oxytocin administration sharpens mind-reading skills (Domes et al., 2007), enhances understanding of other's perspective (Ditzen et al., 2009), and modulates evaluation of other's trustworthiness (Kosfeld et al., 2005). The cognition of self and other are closely interrelated and partly share the same brain network. For example, the medial prefrontal cortex is involved in other's mental state and personality inference tasks (Mitchell et al., 2002, 2004) as well as in evaluation of one's own personality traits (Johnson et al., 2002). Of note, oxytocin administration modulates the medial prefrontal cortex activity (Sripada et al., 2013).

The understanding of others' perspectives and empathic responses also relies on the ability to recognize self-other differences. Oxytocin administration mediates the activation of brain areas, e.g., the posterior temporal sulcus (Pincus et al., 2010; Gordon et al., 2013), that are involved in

OPEN ACCESS

Edited by:

Georg Northoff,

University of Ottawa, Canada

Reviewed by:

Yina Ma,

Beijing Normal University, China

*Correspondence:

Valentina Colonnello

valentina.colonnello@psychologie. uni-freiburg.de:

Markus Heinrichs

heinrichs@psychologie.uni-freiburg.de

Received: 30 July 2015 Accepted: 11 February 2016 Published: 29 February 2016

Citation:

Colonnello V and Heinrichs M (2016) Oxytocin and Self-Consciousness.

Front. Hum. Neurosci. 10:67. doi: 10.3389/fnhum.2016.00067 mentalizing and processing self-other distinction (Decety and Lamm, 2007). Oxytocin is probably involved in both other- and self-related processing.

Two fundamental issues regarding the oxytocinergic system and self-consciousness are of specific relevance. First, oxytocin is synthesized in the paraventricular and supraoptic nuclei of the hypothalamus and processed to the posterior pituitary lobe, through axonal projections, for release into peripheral circulation. In addition, dendrites release oxytocin into extracellular space, from where it diffuses to several distant areas in the brain. Oxytocin receptors have been found in several brain areas, including the periacqueductal gray, putamen, insula, amygdala, nucleus accumbens, and prefrontal cortex (Sofroniew, 1983; Tribollet et al., 1992; Meyer-Lindenberg et al., 2011). Of note, oxytocin diffuses from evolutionarily ancient areas primarily involved in arousal states and emotion expression to more recent distal brain areas involved in cognitively mediated processes.

The second relevant issue concerns the definition of self-consciousness. There is still no consensus on what self-consciousness is or how it works. Over the past century, scholars from different disciplines and theoretical approaches have proposed several models of consciousness (Panksepp, 1998; Damasio, 1999; Gallagher, 2000; Metzinger, 2003; Morin, 2006; Edelman et al., 2011; Vandekerckhove and Panksepp, 2011), which for the sake of brevity are not discussed here.

Here, we focus on the most recent, prominent psychobiological and evolutionarily-based perspectives, that conceptualize consciousness levels as developing in a continuum throughout phylogenesis (Tulving, 1985; Vandekerckhove and Panksepp, 2009, 2011). In this view, three interdependent levels of self-consciousness are identifiable: (i) the non-reflective, affectively rich anoetic (unknowing) consciousness, which is believed to involve the basal subcortical system, 
extending from brainstem to hypothalamus to central thalamic nuclei; (ii) noetic (knowing) learning-based consciousness, which relies on activating the lower subcortical ganglia and upper limbic cortical midline structures; and (iii) reflective, metacognitive autonoetic (self-knowing) consciousness, which represents a recent achievement of human evolution and relies on associative neocortical brain areas.

Experiential anoetic consciousness occurs without the cognitively mediated self-observation of one's own action. It is conceptualized as direct, unreflective affective and sensorialperceptual experience of the world and self; it represents a primary form of first-person phenomenal "self-experience" and is rooted in the subcortical emotional systems that humans share with lower animals (Vandekerckhove and Panksepp, 2009). Although one's attention is apparently toward the external environment rather than toward oneself, this basic level of consciousness still implies the presence of a minimal unifying implicit instance of self that enables the individual to perceive and to approach, or avoid, the surrounding environment, based on affective experience (Tulving, 1985; Vogeley and Fink, 2003; Vandekerckhove and Panksepp, 2009).

Cross-species studies suggest, that oxytocin influences anoetic consciousness. Specifically, oxytocin administration is associated with changes in affective experience and modulation of unreflective/instinctual proximity of the self toward unfamiliar others. For example, oxytocin modulates social affiliation (Nelson and Panksepp, 1998), facilitates approach toward unfamiliar pups in female rats (Pedersen et al., 1992), enhances social motivation in adult male rats and mice (Lukas et al., 2011), reduces separation distress vocalizations in abruptly isolated rat pups (Insel and Winslow, 1991), enhances confidence behavior in chicks (Panksepp, 2009), while facilitating partner-preference formation in voles (Insel and Hulihan, 1995). Given the limited self-reflective abilities in animals, these findings stress the role of oxytocin in influencing the unreflective anoetic form of consciousness and related instinctual emotional behaviors.

In humans, oxytocin administration facilitates the sensitivity and processing of explicit and masked emotional expressions (Leknes et al., 2012; Domes et al., 2013; Prehn et al., 2013; Kanat et al., 2015) and words with evolutionarily self-relevant values (Heinrichs et al., 2004; Unkelbach et al., 2008), prior to their full cognitive evaluation. Presumably, oxytocin facilitates the processing of evolutionarily self-relevant social stimuli and regulates the approach to novel, self-unrelated social stimuli by increasing the salience of social stimuli (Prehn et al., 2013) while reducing stress-reactivity (Heinrichs et al., 2003) and promoting feelings of self-confidence (Colonnello and Heinrichs, 2014).

Oxytocin administration likely affects noetic levels of self-consciousness. This level of consciousness is rooted in lower anoetic levels and is associated with learning-based self-awareness and the recognition of oneself as "me," that is, the object of one's own observation and the perception of "me" as distinct from "other." We found, that oxytocin influences implicit self-description: oxytocin administration facilitated the tendency to associate self-related words with positive adjectives in healthy men during an implicit association task (Colonnello and Heinrichs, 2014). In addition, intranasal oxytocin administration sharpens explicit selfand other-recognition during the presentation of videos showing photos of one's own face morphing into those of an unfamiliar individual, and vice versa. Specifically, participants who received intranasal administration of oxytocin were facilitated in the self-other distinction of one's own and other's facial features, regardless of the morphing direction. This effect was associated with rating one's own face and other's faces as comparably pleasant, indicating the facilitation of acceptance of self and others (Colonnello et al., 2013).

Oxytocin's role in enhancing distinctions between self- and other-related stimuli is corroborated by a study on pain perception. In this study, participants who received oxytocin exhibited different responses to visualizations of self- and other-directed painful stimulation. They rated their imaginings of personally experienced pain as less stressful than their thoughts of pain experienced by others (Abu-Akel et al., 2015), which suggests a link between oxytocin-induced dampening of stress reactivity, enhanced self-other distinction, and increased attention to others' needs.

The most complex level of self-consciousness, referred to as autonoetic comprises metacognitive tasks, reflection on oneself and one's experience, and mental time traveling in one's own past and future (Suddendorf and Corballis, 1997; Vandekerckhove and Panksepp, 2009). Empirical studies have indicated, that the oxytocin system modulates autonoetic self-consciousness. As Cardoso and colleagues demonstrated, increased levels of oxytocin facilitate the recollection of personal memories and positive social affiliation memories (Cardoso et al., 2014), as well as the tendency to rate oneself with positive personality traits in self-report questionnaires (Cardoso et al., 2012). Notably, oxytocin's influences on autonoetic levels of consciousness are based on individual differences and attachment styles (Bartz et al., 2011). Future studies should investigate whether the effects of oxytocin on autobiographical memories and self-processing might also be linked to an increase in sensitivity toward one's own attachment representations, regardless of their valence.

While the current sparse data converge in indicating that oxytocin is among the neuromodulators implicated in selfconsciousness, it is worth stressing that this research area is still in its infancy and further studies are warranted. But what specific research paradigms would deepen the understanding of oxytocin's role in self-consciousness? Which clinical conditions presenting changes in self-consciousness would benefit from integrating treatments with oxytocin administration?

Undoubtedly, the neuropeptide oxytocin is drawing clinicians' attention due to its effects on several aspects in the social domain. As we previously proposed (Colonnello et al., 2013; Colonnello and Heinrichs, 2014), studies of oxytocin's effects should consider changes not only in one's perceptions of others but also in the processing of self-related information. From the evolutionary and neuroscience perspective, it is plausible that oxytocin affects self-relatedness processing thanks to involvement of the subcortical-cortical midline structures, (Northoff and Panksepp, 2008). Further, at a higher cognitive level, oxytocin likely influences self- and other-related cognition 
by modulating the brain network activity involved in the shared neural representations of others and self (Lombardo et al., 2010).

Thus, oxytocin's influences on several aspects of selfconsciousness and on the interdependence between selfconsciousness levels in clinical conditions characterized by alteration of self and other processing cry out for further research attention. The current paucity of data on the oxytocin's effects on noetic self-consciousness also encourages further investigation of its influences on self-other distinction.

Of note, self-recognition and the sense of self-ownership are among the mechanisms implicated in functional empathic responses. Thus, such investigations would be crucial to furthering our understanding of oxytocin's role in the relationship between self-other distinction and the ability to shift from self-oriented to other-person-oriented perspectives, as well as its role in self-other distinction, and prosocial behavior, especially in light of the close link between interoception and empathy (Ernst et al., 2013). In addition, it would be important to address questions regarding oxytocin's effects on the noetic knowledge of self-agency (i.e., perception of being the author of one's own actions) that is likely to be altered in various clinical conditions (Belayachi and Van der Linden, 2010; Synofzik et al., 2010). The potential effects of oxytocin administration should also be studied in individuals with dysmorphic disorders and in patients with neuropsychological

\section{REFERENCES}

Abu-Akel, A., Palgi, S., Klein, E., Decety, J., and Shamay-Tsoory, S. (2015). Oxytocin increases empathy to pain when adopting the other-but not the self-perspective. Soc. Neurosci. 10, 7-15. doi: 10.1080/17470919.2014.9 48637

Bartz, J. A., Zaki, J., Bolger, N., and Ochsner, K. N. (2011). Social effects of oxytocin in humans: context and person matter. Trends Cogn. Sci. 15, 301-309. doi: 10.1016/j.tics.2011.05.002

Belayachi, S., and Van der Linden, M. (2010). Feeling of doing in obsessive-compulsive checking. Conscious. Cogn. 19, 534-546. doi: 10.1016/j.concog.2010.02.001

Cardoso, C., Ellenbogen, M. A., and Linnen, A. M. (2012). Acute intranasal oxytocin improves positive self-perceptions of personality. Psychopharmacology (Berl). 220, 741-749. doi: 10.1007/s00213-011-2527-6

Cardoso, C., Orlando, M. A., Brown, C. A., and Ellenbogen, M. A. (2014). Oxytocin and enhancement of the positive valence of social affiliation memories: an autobiographical memory study. Soc. Neurosci. 9, 186-195. doi: 10.1080/17470919.2013.873079

Colonnello, V., Chen, F. S., Panksepp, J., and Heinrichs, M. (2013). Oxytocin sharpens self-other perceptual boundary. Psychoneuroendocrinology 38, 2996-3002. doi: 10.1016/j.psyneuen.2013.08.010

Colonnello, V., and Heinrichs, M. (2014). Intranasal oxytocin enhances positive self-attribution in healthy men. J. Psychosom. Res. 77, 415-419. doi: 10.1016/j.jpsychores.2014.06.016

Damasio, A. R. (1999). The Feeling of What Happens: Body and Emotion in the Making of Consciousness. New York, NY: Harcourt Brace.

Decety, J., and Lamm, C. (2007). The role of the right temporoparietal junction in social interaction: how low-level computational processes contribute to meta-cognition. Neuroscientist 13, 580-593. doi: 10.1177/1073858407304654

Ditzen, B., Schaer, M., Gabriel, B., Bodenmann, G., Ehlert, U., and Heinrichs, M. (2009). Intranasal oxytocin increases positive communication and reduces cortisol levels during couple conflict. Biol. Psychiatry 65, 728-731. doi: 10.1016/j.biopsych.2008.10.011 disorders displaying altered "noetic" explicit knowledge of their own body boundaries.

Given that levels of self-consciousness unfold over development and that ontogenetic development recapitulates the phylogenetic development, elucidating oxytocin's influences on the interdependence between self-consciousness levels would also be crucial. Because oxytocin plays a role in social bond formation and in regulating stress responses (Heinrichs et al., 2003) and its influences on autonoetic levels vary as a function of prior attachment experiences (Bartz et al., 2011), the relation between early social environment, alterations in central oxytocin transmission, and development of noetic and autonoetic self-consciousness warrants extensive investigation through longitudinal studies.

Finally, future studies should devote effort to addressing the potential therapeutic role of the oxytocin system (Heinrichs and Domes, 2008; Heinrichs et al., 2009; Meyer-Lindenberg et al., 2011). By buffering self-disclosure and "re-editing" of self-withothers experiences in psychotherapy, oxytocin administration may help create an affective psychobiological context for facilitating therapeutic changes.

\section{AUTHOR CONTRIBUTIONS}

All authors listed, have made substantial, direct and intellectual contribution to the work, and approved it for publication.

Domes, G., Heinrichs, M., Michel, A., Berger, C., and Herpertz, S. C. (2007). Oxytocin improves "mind-reading" in humans. Biol. Psychiatry 61, 731-733. doi: 10.1016/j.biopsych.2006.07.015

Domes, G., Sibold, M., Schulze, L., Lischke, A., Herpertz, S. C., and Heinrichs, M. (2013). Intranasal oxytocin increases covert attention to positive social cues. Psychol. Med. 43, 1747-1753. doi: 10.1017/S0033291712002565

Edelman, G. M., Gally, J. A., and Baars, B. J. (2011). Biology of consciousness. Front. Psychol. 2:4. doi: 10.3389/fpsyg.2011.00004

Ernst, J., Northoff, G., Böker, H., Seifritz, E., and Grimm, S. (2013). Interoceptive awareness enhances neural activity during empathy. Hum. Brain Mapp. 34, 1615-1624. doi: 10.1002/hbm.22014

Gallagher, I. (2000). Philosophical conceptions of the self: implications for cognitive science. Trends Cogn. Sci. 4, 14-21. doi: 10.1016/S13646613(99)01417-5

Gordon, I., Vander Wyk, B. C., Bennett, R. H., Cordeaux, C., Lucas, M. V., Eilbott, J. A., et al. (2013). Oxytocin enhances brain function in children with autism. Proc. Nat. Acad. Sci. U.S.A. 110, 20953-20958. doi: 10.1073/pnas.13128 57110

Heinrichs, M., Baumgartner, T., Kirschbaum, C., and Ehlert, U. (2003). Social support and oxytocin interact to suppress cortisol and subjective responses to psychosocial stress. Biol. Psychiatry 54, 1389-1398. doi: 10.1016/S00063223(03)00465-7

Heinrichs, M., and Domes, G. (2008). Neuropeptides and social behavior: effects of oxytocin and vasopressin in humans. Prog. Brain Res. 170, 337-350. doi: 10.1016/S0079-6123(08)00428-7

Heinrichs, M., Meinlschmidt, G., Wippich, W., Ehlert, U., and Hellhammer, D. H. (2004). Selective amnesic effects of oxytocin on human memory. Physiol. Behav. 83, 31-38. doi: 10.1016/S0031-9384(04)00346-4

Heinrichs, M., von Dawans, B., and Domes, G. (2009). Oxytocin, vasopressin, and human social behavior. Front. Neuroendocrinol. 30, 548-557. doi: 10.1016/j.yfrne.2009.05.005

Insel, T. R., and Hulihan, T. J. (1995). A gender-specific mechanism for pair bonding: oxytocin and partner preference formation in monogamous voles. Behav. Neurosci. 109, 782-789. doi: 10.1037/0735-7044.109.4.782 
Insel, T. R., and Winslow, J. T. (1991). Central administration of oxytocin modulates the infant rats response to social isolation. Eur. J. Pharmacol. 203, 149-152. doi: 10.1016/0014-2999(91)90806-2

Johnson, S. C., Baxter, L. C., Wilder, L. S., Pipe, J. G., Heiserman, J. E., and Prigatano, G. P. (2002). Neural correlates of self-reflection. Brain 125, 1808-1814. doi: 10.1093/brain/awf181

Kanat, M., Heinrichs, M., Schwarzwald, R., and Domes, G. (2015). Oxytocin attenuates neural reactivity to masked threat cues from the eyes. Neuropsychopharmacology 40, 287-295. doi: 10.1038/npp.2014.183

Kosfeld, M., Heinrichs, M., Zak, P. J., Fischbacher, U., and Fehr, E. (2005). Oxytocin increases trust in humans. Nature 435, 673-676. doi: 10.1038/nature03701

Leknes, S., Wessberg, J., Ellingsen, D. M., Chelnokova, O., Olausson, H., and Laeng, B. (2012). Oxytocin enhances pupil dilation and sensitivity to 'hidden'emotional expressions. Soc. Cogn. Affect. Neurosci. 8, 741-749. doi: $10.1093 / \mathrm{scan} / \mathrm{nss} 062$

Lombardo, M. V., Chakrabarti, B., Bullmore, E. T., Wheelwright, S. J., Sadek, S. A., Suckling, J., et al. (2010). Shared neural circuits for mentalizing about the self and others. J. Cogn. Neurosci. 22, 1623-1635. doi: 10.1162/jocn.2009. 21287

Lukas, M., Toth, I., Reber, S. O., Slattery, D. A., Veenema, A. H., and Neumann, I. D. (2011). The neuropeptide oxytocin facilitates pro-social behavior and prevents social avoidance in rats and mice. Neuropsychopharmacology 36, 2159-2168. doi: 10.1038/npp.2011.95

Metzinger, T. (2003). Being No One. Cambridge, MA: MIT Press.

Meyer-Lindenberg, A., Domes, G., Kirsch, P., and Heinrichs, M. (2011). Oxytocin and vasopressin in the human brain: social neuropeptides for translational medicine. Nat. Rev. Neurosci. 12, 524-538. doi: 10.1038/ nrn3044

Mitchell, J. P., Heatherton, T. F., and Macrae, C. N. (2002). Distinct neural systems subserve person and object knowledge. Proc. Nat. Acad. Sci. U.S.A. 99, 15238-15243. doi: 10.1073/pnas.232395699

Mitchell, J. P., Macrae, C. N., and Banaji, M. R. (2004). Encoding-specific effects of social cognition on the neural correlates of subsequent memory. J. Neurosci. 24, 4912-4917. doi: 10.1523/JNEUROSCI.0481-04.2004

Morin, A. (2006). Levels of consciousness and self-awareness: a comparison and integration of various neurocognitive views. Conscious. Cogn. 15, 358-371. doi: 10.1016/j.concog.2005.09.006

Nelson, E. E., and Panksepp, J. (1998). Brain substrates of infant-mother attachment: contributions of opioids, oxytocin, and norepinephrine. Neurosci. Biobehav. Rev. 22, 437-452. doi: 10.1016/S0149-7634(97)00052-3

Northoff, G., and Panksepp, J. (2008). The trans-species concept of self and the subcortical-cortical midline system. Trends Cogn. Sci. 12, 259-264. doi: 10.1016/j.tics.2008.04.007

Panksepp, J. (1998). Affective Neuroscience: The Foundations of Human and Animal Emotions. Oxford: Oxford university press.

Panksepp, J. (2009). Primary process affects and brain oxytocin. Biol. Psychiatry 65, 725-727. doi: 10.1016/j.biopsych.2009.02.004

Pedersen, C. A., Caldwell, J. D., Peterson, G., Walker, C. H., and Mason, G. A. (1992). Oxytocin activation of maternal behavior in the rata. Ann. N.Y. Acad. Sci. 652, 58-69. doi: 10.1111/j.1749-6632.1992.tb34346.x
Pincus, D., Kose, S., Arana, A., Johnson, K., Morgan, P. S., Borckardt, J., et al. (2010). Inverse effects of oxytocin on attributing mental activity to others in depressed and healthy subjects: a double-blind placebo controlled FMRI study. Front. Psychiatry 1:134. doi: 10.3389/fpsyt.2010.00134

Prehn, K., Kazzer, P., Lischke, A., Heinrichs, M., Herpertz, S. C., and Domes, G. (2013). Effects of intranasal oxytocin on pupil dilation indicate increased salience of socioaffective stimuli. Psychophysiology 50, 528-537. doi: 10.1111/psyp. 12042

Sofroniew, M. V. (1983). Vasopressin and oxytocin in the mammalian brain and spinal cord. Trends Neurosci. 6, 467-472. doi: 10.1016/0166-2236(83) 90221-7

Sripada, C. S., Phan, K. L., Labuschagne, I., Welsh, R., Nathan, P. J., and Wood, A. G. (2013). Oxytocin enhances resting-state connectivity between amygdala and medial frontal cortex. Int. J. Neuropsychopharmacol. 16, 255-260. doi: $10.1017 /$ S1461145712000533

Suddendorf, T., and Corballis, M. C. (1997). Mental time travel and the evolution of the human mind. Genet. Soc. Gen. Psychol. Monogr. 123, 133-167.

Synofzik, M., Thier, P., Leube, D. T., Schlotterbeck, P., and Lindner, A. (2010). Misattributions of agency in schizophrenia are based on imprecise predictions about the sensory consequences of one's actions. Brain 133, 262-271. doi: 10.1093/brain/awp291

Tribollet, E., Dubois-Dauphin, M., Dreifuss, J. J., Barberis, C., and Jard, S. (1992). Oxytocin receptors in the central nervous system. Ann. N.Y. Acad. Sci. 652, 29-38. doi: 10.1111/j.1749-6632.1992.tb34343.x

Tulving, E. (1985). Memory and consciousness. Can. Psychol. 26, 1-12. doi: $10.1037 / \mathrm{h} 0080017$

Unkelbach, C., Guastella, A. J., and Forgas, J. P. (2008). Oxytocin selectively facilitates recognition of positive sex and relationship words. Psychol. Sci. 19, 1092-1094. doi: 10.1111/j.1467-9280.2008.02206.x

Vandekerckhove, M., and Panksepp, J. (2009). The flow of anoetic to noetic and autonoetic consciousness: a vision of unknowing (anoetic) and knowing (noetic) consciousness in the remembrance of things past and imagined futures. Conscious. Cogn. 18, 1018-1028. doi: 10.1016/j.concog.2009.08.002

Vandekerckhove, M., and Panksepp, J. (2011). A neurocognitive theory of higher mental emergence: from anoetic affective experiences to noetic knowledge and autonoetic awareness. Neurosci. Biobehav. Rev. 35, 2017-2025. doi: 10.1016/j.neubiorev.2011.04.001

Vogeley, K., and Fink, G. R. (2003). Neural correlates of the first-personperspective. Trends Cogn. Sci. 7, 38-42. doi: 10.1016/S1364-6613(02)00003-7

Conflict of Interest Statement: The authors declare that the research was conducted in the absence of any commercial or financial relationships that could be construed as a potential conflict of interest.

Copyright () 2016 Colonnello and Heinrichs. This is an open-access article distributed under the terms of the Creative Commons Attribution License (CC BY). The use, distribution or reproduction in other forums is permitted, provided the original author(s) or licensor are credited and that the original publication in this journal is cited, in accordance with accepted academic practice. No use, distribution or reproduction is permitted which does not comply with these terms. 